\title{
CYCLICAL ASPECTS OF BLACK UNEMPLOYMENT: AN EMPIRICAL ANALYSIS
}

\author{
Nozar Hashemzadeh and Burl F. Long*
}

\section{Introduction}

Business cycle theorists have long recognized that certain industries and sub-groups of the labor force are more susceptible to cyclical influences than others. The traditional view is that both output and employment in durable goods industries tend to be more volatile relative to industries that produce nondurable goods and services. In analyzing the dynamics of business cycles and their effects on the various subsectors of the economy, it is also instructive to examine the differential impact of changes in aggregate economic activity on employment by race and ethnic origin. For example, during the recession of 1980-1982, the jobless rates for black, Mexican, Puerto Rican, and Cuban workers were approximately double those of white workers. The evidence in Table 1 suggests that the disparities in unemployment rates of whites and blacks have generally persisted over the past three decades.

This paper examines, in a national perspective, the extent to which the "typical" unemployment cycle and its duration differ for non-whites. ${ }^{1}$ Drawing on annual data from 1950 to 1982 , the study attempts to show how the burden of unemployment shifts from whites to blacks and vice-versa over the course of the business cycle. In addition, the extent to which the black unemployment cycle has been influenced by the increased labor participation of white females is investigated. This analysis offers greater insight as to the cause of rising long-run employment among black males.

\footnotetext{
- Associate Professor of Economics, Radford University and Professor of Food and Resource Economics, University of Florida, formerly Professor of Economics, Radford University. The authors are indebted to Dr. Henry Ponder, President of Fisk University, for his thoughtful comments and insights on an earlier draft of this paper. Appreciation is also extended to Dr. Earl Brown, Radford University, for reviewing a draft of the paper.
}

\section{Measures of Variability}

Numerous methods have been used for measuring and comparing the incidence of unemployment among various sub-groups in the labor force. One of the simplest methods often noted in the literature is the relative unemployment differential. This measure is computed by dividing the unemployment rate of the target population by either the overall unemployment rate or the unemployment rate for a selected group. As shown in Figure 1, the ratio statistic for black to white unemployment has generally oscillated between 1.67 and 2.31 for the period 1950-1982. Based on rather limited data, some authors (Gilman and others) have concluded that the black to white unemployment ratio typically increases in times of economic expansion or prosperity and falls during the contraction phase of the business cycle.

Focusing only on this ratio would be misleading. The ratio would imply that blacks are better off compared to whites during the recessionary phase of the business cycle and worse off during economic expansion. Although a useful concept, the relative unemployment ratio can hardly be used as an analytical tool for understanding some of the more subtle aspects of cyclical variability in unemployment rates for various groups. The relative unemployment ratio is useless in comparing the change in unemployment rates for a specific group at different phases of the cycle. ${ }^{2}$ As suggested by Gilroy, the relative cyclical variability of unemployment among subgroups could be better understood by comparing the standard deviations of the respective unemployment series. Using this measure, Gilroy concludes that, for the period 1954 to 1973, the standard deviations as well as the relative variance of unemployment rates were greater for blacks than for whites.

To better elucidate the underlying patterns of cyclical variability in black-white unemployment rates, annual unemployment observations relating to these sub-groups are graphed 
Table 1

U.S. Civilian Unemployment, by Race 1950-1982

(Seasonally Adjusted)

\begin{tabular}{|c|c|c|c|c|c|}
\hline Year & $\begin{array}{c}\text { Total } \\
\text { Unemployment Rate }\end{array}$ & White & $\begin{array}{c}\text { Black \& } \\
\text { Other }\end{array}$ & $\begin{array}{c}\text { Ratio } \\
\text { Black/Total } \\
\end{array}$ & $\begin{array}{c}\text { Ratio } \\
\text { Black/White }\end{array}$ \\
\hline 1950 & 5.3 & 4.9 & 9.0 & 1.70 & 1.84 \\
\hline 1951 & 3.3 & 3.1 & 5.3 & 1.61 & 1.71 \\
\hline 1952 & 3.0 & 2.8 & 5.4 & 1.80 & 1.93 \\
\hline 1953 & 2.9 & 2.7 & 4.5 & 1.55 & 1.67 \\
\hline 1954 & 5.5 & 5.0 & 9.9 & 1.80 & 1.98 \\
\hline 1955 & 4.4 & 3.9 & 8.7 & 1.98 & 2.23 \\
\hline 1956 & 4.1 & 3.6 & 8.3 & 2.02 & 2.31 \\
\hline 1957 & 4.3 & 3.8 & 7.9 & 1.84 & 2.08 \\
\hline 1958 & 6.8 & 6.1 & 12.6 & 1.85 & 2.07 \\
\hline 1959 & 5.5 & 4.8 & 10.7 & 1.95 & 2.23 \\
\hline 1960 & 5.5 & 4.9 & 10.2 & 1.85 & 2.08 \\
\hline 1961 & 6.7 & 6.0 & 12.4 & 1.85 & 2.07 \\
\hline 1962 & 5.5 & 4.9 & 10.9 & 1.98 & 2.22 \\
\hline 1963 & 5.7 & 5.0 & 10.8 & 1.89 & 2.16 \\
\hline 1964 & 5.2 & 4.6 & 9.6 & 1.85 & 2.09 \\
\hline 1965 & 4.5 & 4.1 & 8.1 & 1.80 & 1.98 \\
\hline 1966 & 3.8 & 3.3 & 7.3 & 1.93 & 2.21 \\
\hline 1967 & 3.8 & 3.4 & 7.4 & 1.95 & 2.18 \\
\hline 1968 & 3.6 & 3.2 & 6.7 & 1.86 & 2.09 \\
\hline 1969 & 3.5 & 3.1 & 6.4 & 1.83 & 2.06 \\
\hline 1970 & 4.9 & 4.5 & 8.2 & 1.67 & 1.82 \\
\hline 1971 & 5.9 & 5.4 & 9.9 & 1.68 & 1.83 \\
\hline 1972 & 5.6 & 5.0 & 10.0 & 1.79 & 2.00 \\
\hline 1973 & 4.9 & 4.3 & 8.9 & 1.82 & 2.07 \\
\hline 1974 & 5.6 & 5.0 & 9.9 & 1.77 & 1.98 \\
\hline 1975 & 8.5 & 7.8 & 13.9 & 1.63 & 1.78 \\
\hline 1976 & 7.7 & 7.0 & 13.1 & 1.70 & 1.87 \\
\hline 1977 & 7.0 & 6.2 & 13.1 & 1.87 & 2.11 \\
\hline 1978 & 6.0 & 5.2 & 11.9 & 1.98 & 2.29 \\
\hline 1979 & 5.8 & 5.1 & 11.3 & 1.95 & 2.22 \\
\hline 1980 & 7.1 & 6.3 & 13.1 & 1.85 & 2.08 \\
\hline 1981 & 7.6 & 6.7 & 14.2 & 1.87 & 2.12 \\
\hline 1982 & 9.7 & 8.6 & 17.3 & 1.78 & 2.01 \\
\hline
\end{tabular}

Source: Employment and Training Report of the President, various issues.

in Figures 2 and 3. These figures show the combined effects of business cycles, trend and random movements in the unemployment rate series for the period 1950-1982. The observed unemployment rate patterns reveal two major phenomena. First, the rise in unemployment begins before the business cycle peaks and the decline in unemployment does not begin until recovery is well underway. Second, since the $1960 \mathrm{~s}$, the jobless rate at the end of each recovery period persists at a level higher than at the start of the previous recession. The overall upward trend in the unemployment rate has been marked by seven recessions or nearly eight business cycles for the whole period.

\section{Cyclical Movements}

The observed annual changes for black and white unemployment rates are shown in Table 2 and are graphed in Figure 4. Analysis of the data reveals that the rise in unemployment rates for blacks exceeds those for whites in all the recessionary periods documented since 1950. However, during the expansionary phases of the business cycles, the decline in unemployment rates for blacks is greater than those for whites. This evidence suggests that blacks gain proportionately more from an economic recovery and lose proportionately more during an economic downturn. This finding is at variance with the general implication 
Cyclical Aspects of Black Unemployment: An Empirical Analysis

Figure 1

Black Unemployment Rates Relative to National and White Unemployment Rates, 1950-1982

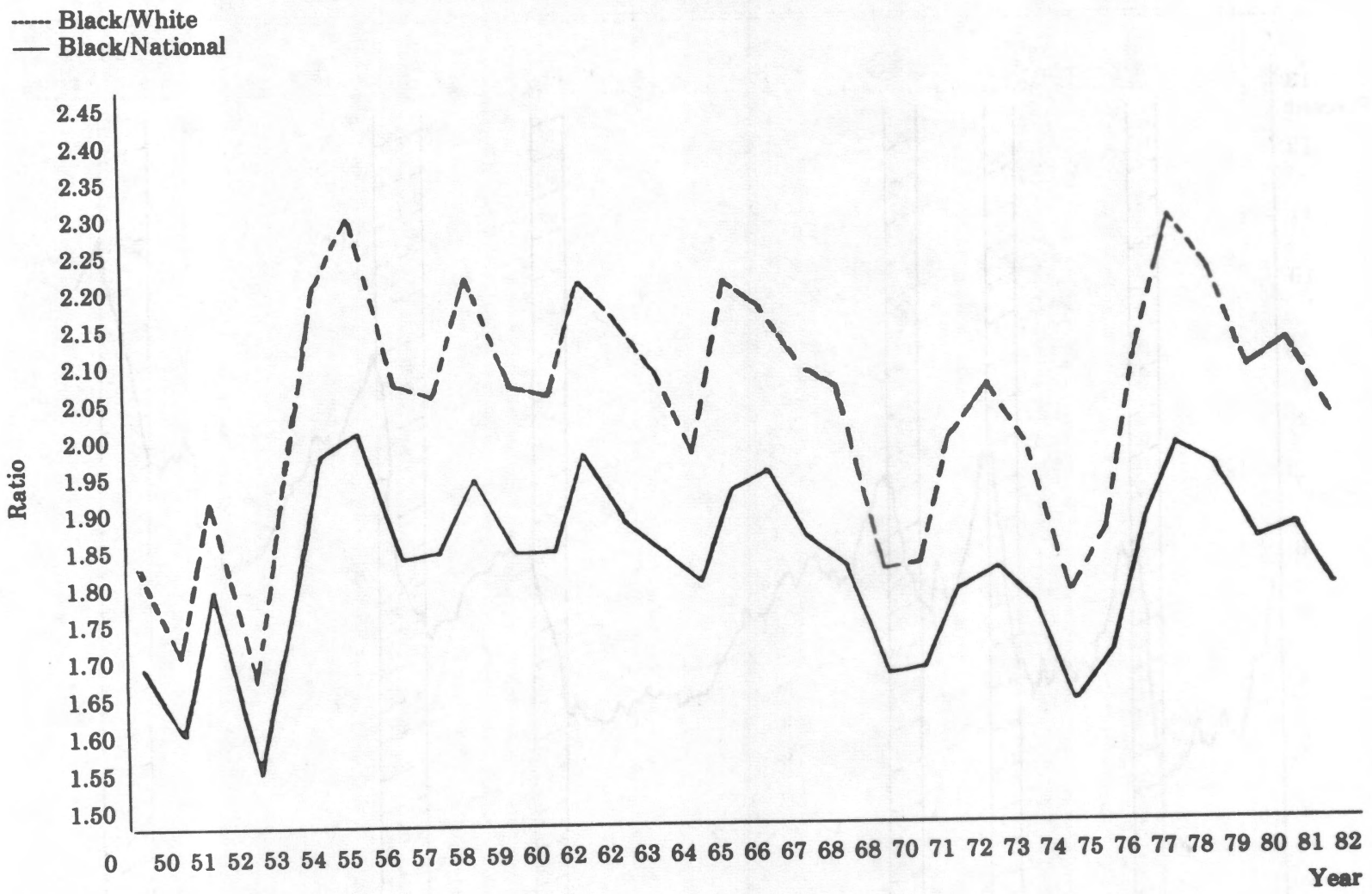


Figure 2

U.S. Civilian Unemployment, 1950-1982

(Seasonally Adjusted)

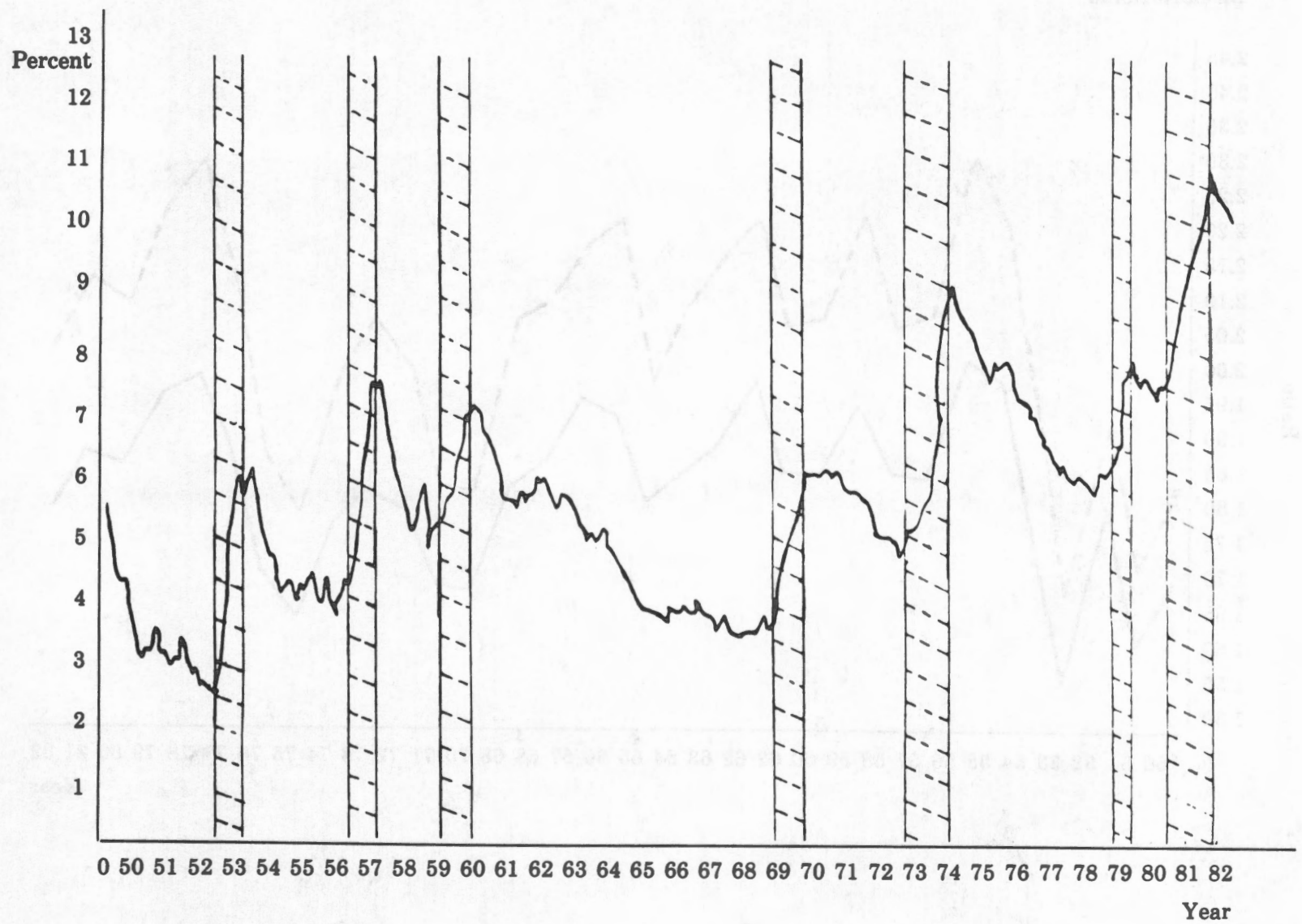

Note: Shaded areas denote recession periods.

Source: U.S. Department of Labor, Bureau of Labor Statistics, July, 1983, Bulletin 2172. 
Figure 3

Black and White Unemployment Rates, 1950-1982

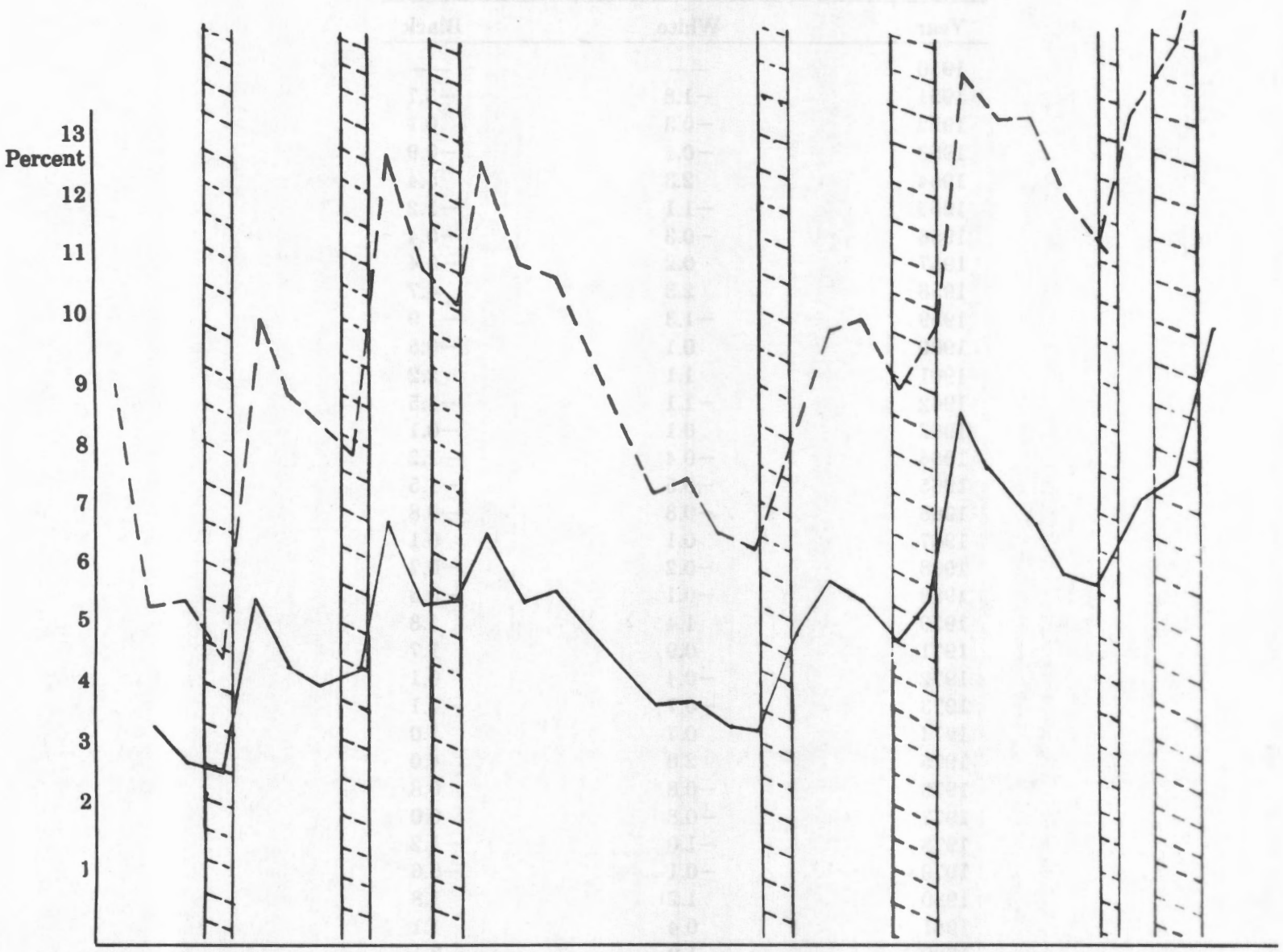

$05051525354555657585960616263646566 \quad 67686970717273747576777879808182$ Note: Shaded areas denote recession periods. 
Table 2

Annual Changes in White and Black Unemployment Rates 1950-1982

\begin{tabular}{lrr}
\hline Year & White & Black \\
\hline 1950 & -- & -- \\
1951 & -1.8 & -3.7 \\
1952 & -0.3 & 0.1 \\
1953 & -0.1 & -0.9 \\
1954 & 2.3 & 5.4 \\
1955 & -1.1 & -1.2 \\
1956 & -0.3 & -0.4 \\
1957 & 0.2 & -0.4 \\
1958 & 2.3 & 4.7 \\
1959 & -1.3 & -1.9 \\
1960 & 0.1 & -0.5 \\
1961 & 1.1 & 2.2 \\
1962 & -1.1 & -1.5 \\
1963 & 0.1 & -0.1 \\
1964 & -0.4 & -1.2 \\
1965 & -0.5 & -1.5 \\
1966 & -0.8 & -0.8 \\
1967 & 0.1 & 0.1 \\
1968 & -0.2 & -0.7 \\
1969 & -0.1 & -0.3 \\
1970 & 1.4 & 1.8 \\
1971 & 0.9 & 1.7 \\
1972 & -0.4 & 0.1 \\
1973 & -0.7 & -1.1 \\
1974 & 0.7 & 1.0 \\
1975 & 2.8 & 4.0 \\
1976 & -0.8 & 0.8 \\
1977 & -0.8 & 0.0 \\
1978 & -1.0 & -1.2 \\
1979 & -0.1 & -0.6 \\
1980 & 1.2 & 1.8 \\
1981 & 0.4 & 1.1 \\
1982 & 1.9 & 3.1 \\
\hline \hline
\end{tabular}




\section{Figure 4}

Changes in White and Black Unemployment Rates During Recessionary Periods, 1950-1982

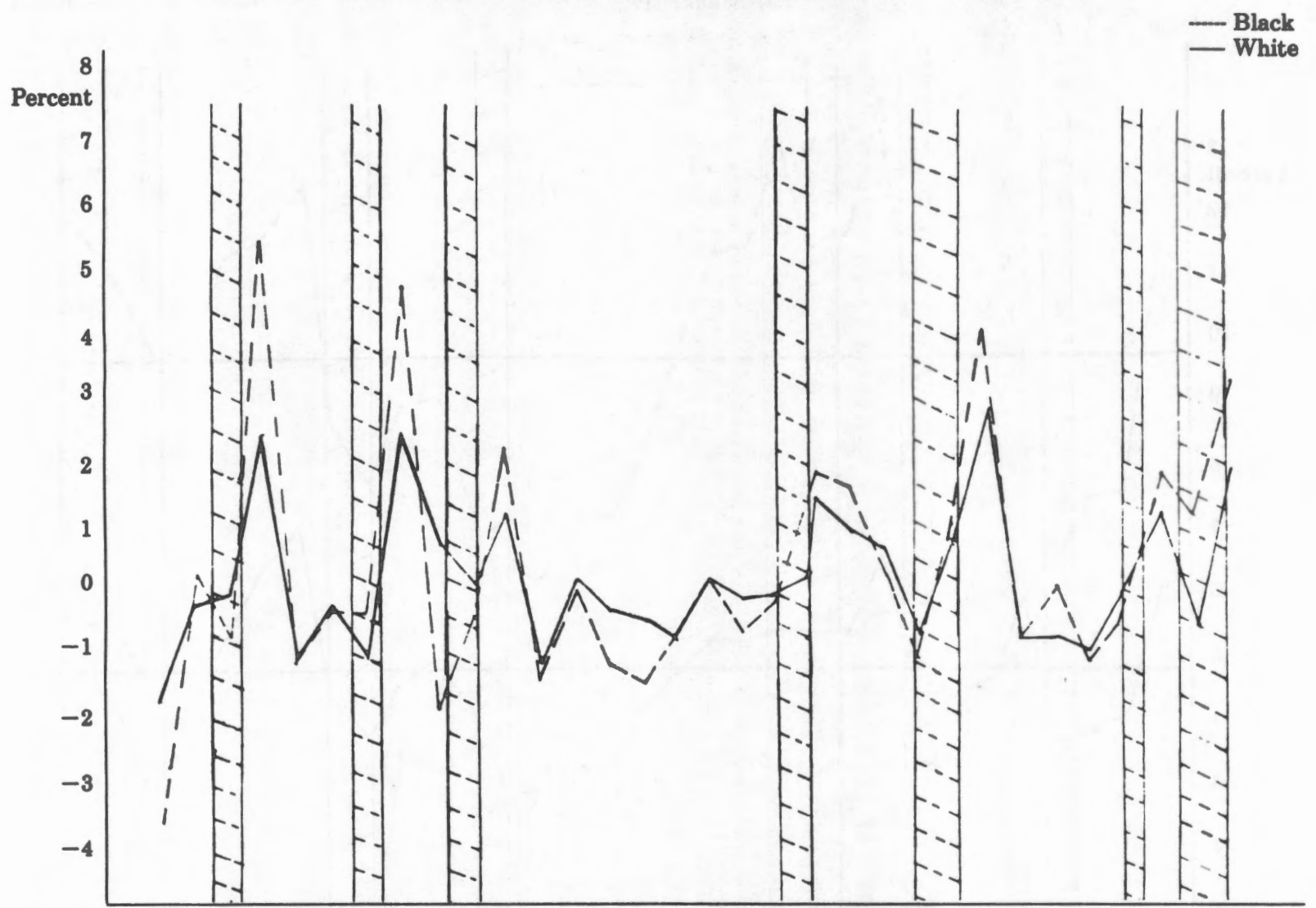

O 505152535455565758596061626364656667686970717273747576777879808182

Note: Shaded areas denote recession periods.

Year

of the relative unemployment differential which holds that blacks somehow fare better than whites during a recession.

The observed oscillations in the unemployment rates series are further explored using frequency domain analysis. As a first step, the trend factor is removed from the original time series. The detrended series, containing only the cyclical component, becomes the input in the spectral analysis of the data. The objective here is to find a series of sine waves which best fit the cyclical variations in the unemployment rate series. Each sine wave is identifiable by its amplitude, phase, duration, and causation. Sinusoid functions in neighboring frequencies are grouped into frequency bands and their coefficients are estimated. Among the statistics estimated is the average squared amplitude of sine waves falling in each frequency band. This estimated spectral density is plotted as a function of frequency bands in Figure 6. The spectral density function shows how the oscillations exhibited in Figure 5 are distributed over the different frequency bands for the two series. The results presented in Figure 6 show that two types of cycles cause most of the variations in the unemployment rate series. These cycles appear to recur every five and ten years, with the ten year cycle causing most of the variations in the black unemployment rates. As expected, whites are not as severely affected by these cycles as are blacks. As to the nature and identity of these cycles, it seems that the relatively shorter cycle corresponds to observed fluctuations in aggregate economic activity. The longer cycle is not so easy to identify. ${ }^{3}$ According to Wesley Mitchell, cycles of 10-12 years duration typically are cycles of building or construction activity. 
Figure 5

Black and White Unemployment Rates Corrected for Trend, 1950-1982

Black

White

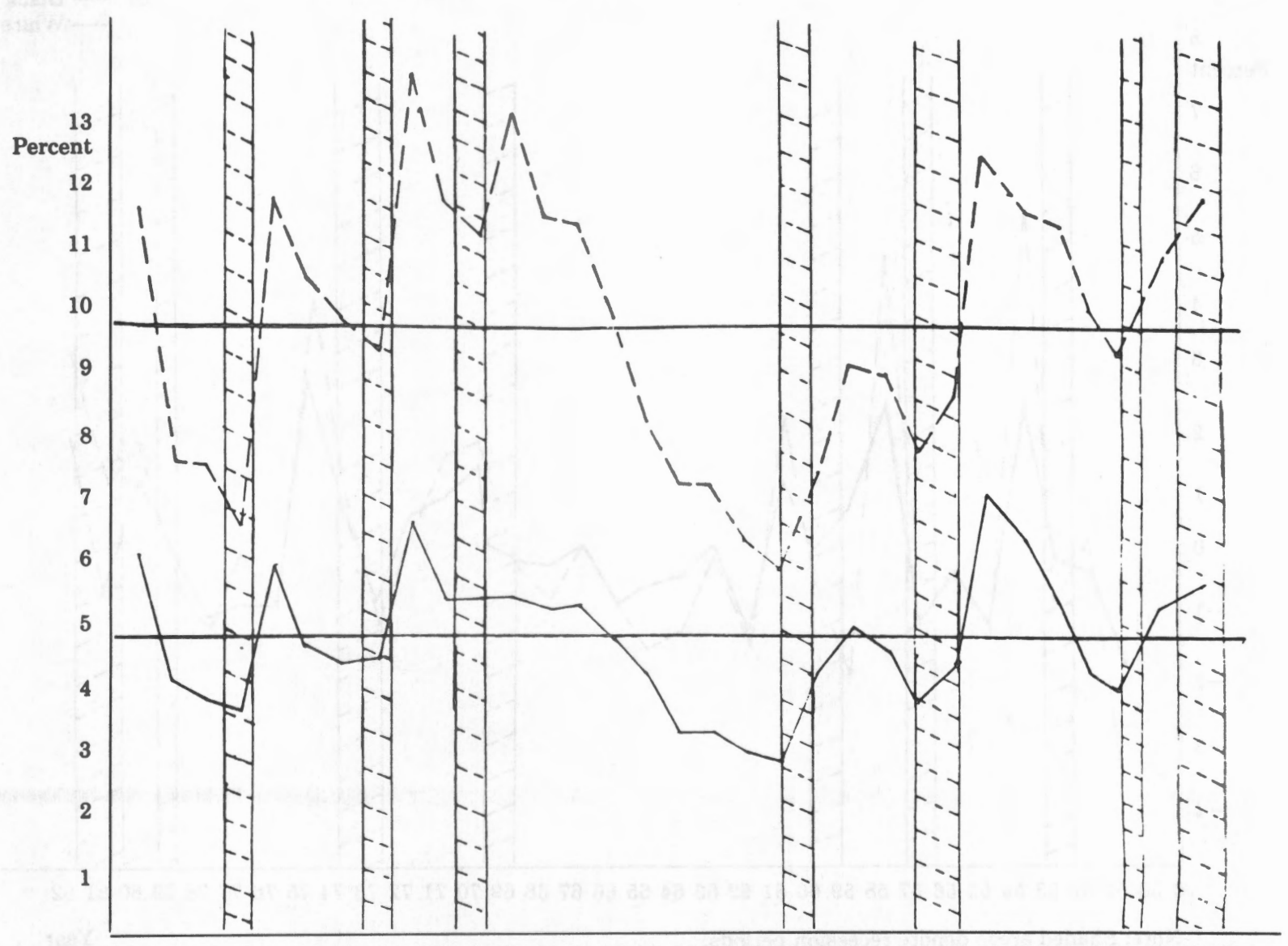

$05051525354555657585960616263646566 \quad 67686970717273747576777879808182$

Note: Shaded areas denote recession periods. 
Figure 6

Estimated Spectral Density Functions for Black and White Series Band Width $=.1563$

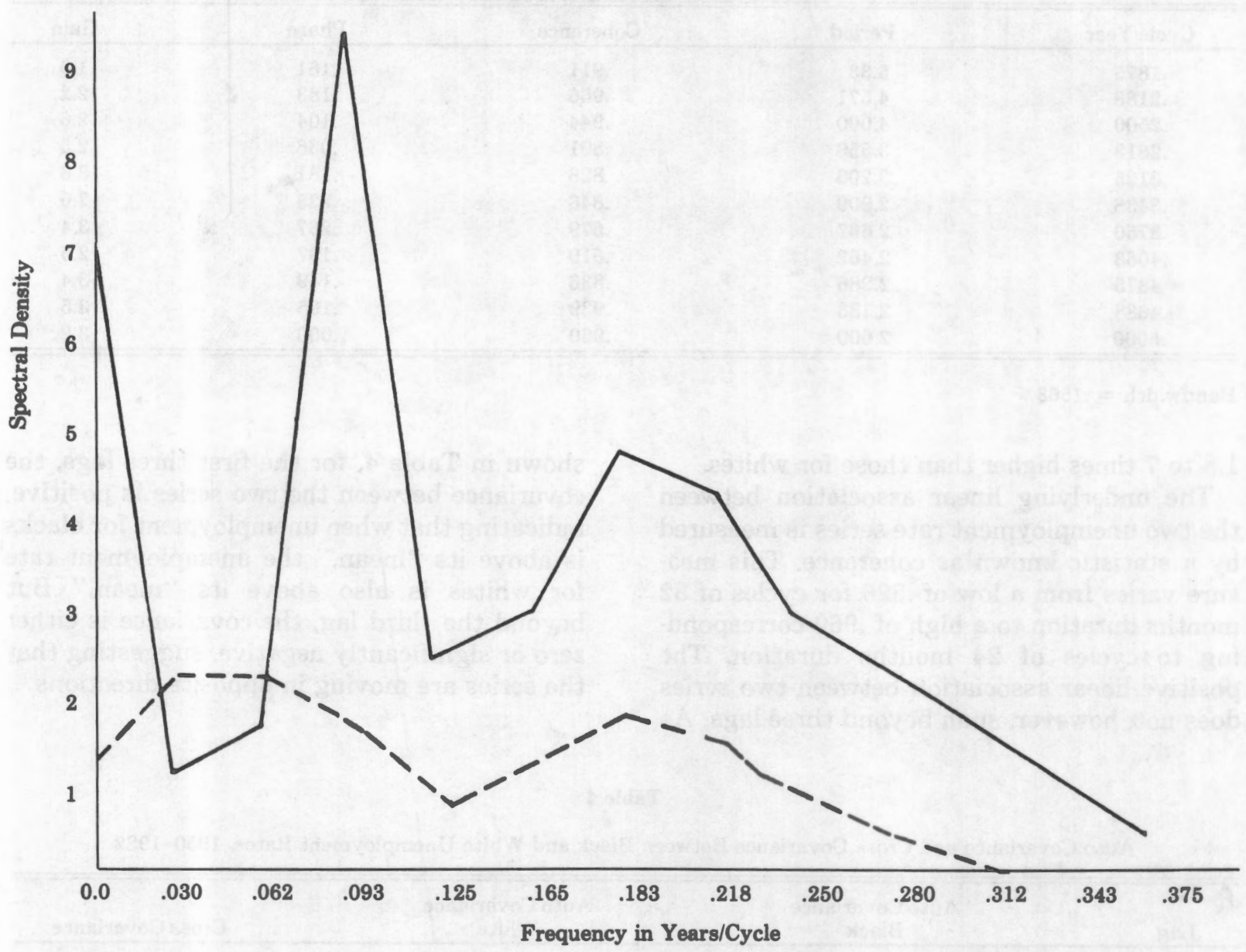

\section{Cycle Statistics}

The phase angle spectrum which shows the timing relationship between the two series at different frequencies is shown in Table 3. This statistic suggests that in all cycles of five years' duration or less, black unemployment tends to exceed white unemployment. This conclusion is consistent with the pattern shown in Figure 5. According to statistics as recent as February 1984, blacks had an average unemployment duration of 23.0 weeks as compared with 18.3 weeks for whites. The comparable data for black males and females were 25.2 and 20.5 weeks as contrasted with 20.7 and 14.6 weeks for white males and females respectively (U.S. Bureau of Labor Statistics). With the onset of a recession, blacks-largely over-represented in low skill and marginal occupations-tend to be laid off or switched to part-time employment several weeks earlier than their white counterparts. As the economy picks up, blacks as a group are not among the first round beneficiaries of expanding employment opportunities.

The gain statistic (Table 3) indicates how the cyclical fluctuations in black unemployment compare with those in white unemployment at different frequencies. It is quite apparent that the cycles shaping observed patterns of black unemployment have amplitudes which are from 
Table 3

Estimated Phase, Coherence, and Gain Statistics of a Cross Spectrum of Detrended Black and White Unemployment Series, 1950-1982

\begin{tabular}{ccccc}
\hline \hline CyclerYear & Period & Coherence & Phase & Gain \\
\hline .1875 & 5.33 & .911 & .161 & .1 .8 \\
.2188 & 4.571 & .956 & .183 & .104 \\
.2500 & 4.000 & .944 & .068 & 2.6 \\
.2813 & 3.556 & .891 & .181 & 2.5 \\
.3125 & 3.200 & .828 & .223 & 3.6 \\
.3438 & 2.909 & .846 & .267 & 7.0 \\
.3750 & 2.667 & .579 & .197 & 3.4 \\
.4063 & 2.462 & .619 & .149 & 2.5 \\
.4375 & 2.286 & .836 & .105 & 3.4 \\
.4688 & 2.133 & .939 & .000 & 3.5 \\
.5000 & 2.000 & .960 & & 3.2 \\
\hline
\end{tabular}

Bandwidth $=.1563$

1.8 to 7 times higher than those for whites.

The underlying linear association between the two unemployment rate series is measured by a statistic known as coherence. This measure varies from a low of $\mathbf{. 5 2 6}$ for cycles of 32 months duration to a high of .960 corresponding to cycles of 24 months duration. The positive linear association between two series does not, however, span beyond three lags. As shown in Table 4, for the first three lags, the covariance between the two series is positive, indicating that when unemployment for blacks is above its "mean," the unemployment rate for whites is also above its "mean." But beyond the third lag, the covariance is either zero or significantly negative, suggesting that the series are moving in opposite directions.

Table 4

Auto Covariance and Cross Covariance Between Black and White Unemployment Rates, 1950-1982

\begin{tabular}{rrrr}
\hline Lag & $\begin{array}{c}\text { Auto Covariance } \\
\text { Black }\end{array}$ & $\begin{array}{c}\text { Auto Covariance } \\
\text { White }\end{array}$ & Cross Covariance \\
\hline 1 & 4.320 & 1.034 & 1.938 \\
2 & 2.499 & .497 & 1.155 \\
3 & 1.261 & .062 & .440 \\
4 & .566 & -.076 & .150 \\
5 & .581 & .130 & .388 \\
6 & .001 & .072 & .241 \\
7 & -.509 & -.057 & -.011 \\
8 & -.864 & -.158 & -.252 \\
9 & -.793 & -.159 & -.323 \\
10 & -.416 & -.088 & -.188 \\
11 & -.226 & -.025 & -.075 \\
13 & -.075 & -.004 & -.011 \\
\hline \hline
\end{tabular}

Covariances Estimated from Spectra 
Impact of Legislation

Beginning in 1964, legislation including the Civil Rights Act, the Economic Opportunity Program and other measures was enacted to enhance employment opportunities for blacks and to reduce or eradicate institutionalized discrimination against minorities. To further assess the possible effects of such legislation on black employment, the unemployment patterns for blacks and whites over two separate time periods have been explored. The first period extends from 1950 to 1967 , and the second period covers the 1966 to 1982 span. In carryng out this investigation, it is hypothesized that the relative gap between the cyclical variability of the two unemployment rate series should have narrowed in the 1966-1982 period as compared with the earlier period. This hypothesis is tested by transforming the detrended data from a time domain to a fre- the gain statistic, which quantifies the volatility in the black unemployment cycle at each specified frequency in relation to the white unemployment cycle. The results of the tests are presented in Table 5.

Although the overall employment situation has deteriorated in recent years, the cyclical gaps between the unemployment rate of blacks and whites appear to have narrowed since 1966. When compared with the first period, the extent of cyclical volatility in black unemployment, as measured by the gain statistic (Table 5, Columns 6 and 7), appears to have dropped considerably during the 1966-1982 period of all frequencies. Moreover, the evidence tends to suggest that there has been some overall improvement in the cyclical correlation between the two time series, implying that the ups and downs in one series are closely followed by the other. On the other hand, the phase

Table 5

Cross Spectral Estimates of Phase, Coherence and Gain Statistics for Black and White Unemployment Series, 1960-1965, 1966-1982

\begin{tabular}{|c|c|c|c|c|c|c|}
\hline \multirow[b]{2}{*}{ Frequency } & \multicolumn{2}{|c|}{ Phase } & \multicolumn{2}{|c|}{ Coherence } & \multicolumn{2}{|c|}{ Gain } \\
\hline & $1950-1965$ & $1966-1982$ & $1950-1865$ & 1966-1882 & $1950-1965$ & 1966-1982 \\
\hline .0000 & .000 & -.000 & .980 & .884 & 12.7 & 3.4 \\
\hline .0625 & -.046 & .273 & .927 & .946 & 11.5 & 3.5 \\
\hline .1250 & .003 & .262 & .799 & .935 & 7.6 & 2.7 \\
\hline .1875 & .121 & .178 & .856 & .950 & 3.5 & 1.9 \\
\hline .2500 & .144 & .166 & .952 & .960 & 3.4 & 1.8 \\
\hline .3125 & .180 & .111 & .943 & .936 & 3.6 & 2.40 \\
\hline .3750 & .235 & -.024 & .903 & .961 & 4.8 & 3.1 \\
\hline .4375 & .082 & -.078 & .904 & .957 & 4.4 & 3.14 \\
\hline .5000 & .000 & -.000 & .908 & .925 & 4.0 & 3.155 \\
\hline
\end{tabular}

quency domain using cross spectrum analysis (Bloomfield, Brillinger, Malinvaud). Treating black unemployment as the crossed series and white unemployment as the input series, a cross spectrum is specified. The main objective here is to analyze the association between the two times series in terms of their cyclic component to determine the pattern of convergence (divergence) that characterizes the data at different frequencies. More specifically, three different statistics are computed for each time period. These are: (a) coherence, which is a measure of linear association between the two series, (b) phase, which indicates the lead or lag of one series as compared to the other, and (c) statistic shows that the black unemployment cycle continues to lead the white cycle over most frequencies.

\section{Participation Rates of White Females}

Since 1950, the labor force participation by white females has increased by approximately two percent a year. Has this development adversely affected the employment opportunities for blacks? In a recent study, Hashemzadeh and Simmons found no significant correlation between increased white female participation rates and increased black male youth unemployment. These authors, however, limited 
their analysis to the investigation of the contemporaneous relationship between the two variables. Practically speaking, employers who practice racial discrimination can only gradually replace their black employees with white females. There is a considerable time lag between the point at which an employer recognizes a new trend in the labor market and the point at which the employer acts to change the composition of his/her work force. In recognition of this phenomenon, the time lag was incorporated into this analysis by means of com- puting cross covariances between black unemployment rates and white female participation rates at several lags. The results are given in Table 6.

For the trend adjusted data, the cross covariances at lag one through four are positive, albeit very small, suggesting that: (a) the relationship between the two variables is not instantaneous, and (b) overall black unemployment is sensitive to increased rates of participation by white females only to a very small extent. In addition, the cross spectrum coher-

Table 6

Auto Covariance and Cross Covariance Between Labor Force Participation Rates of White Females and the Rate of Unemployment Among Black Males, 1950-1982

\begin{tabular}{rccc}
\hline \hline Lag & $\begin{array}{c}\text { Auto Covariance } \\
\text { Participation Rate }\end{array}$ & $\begin{array}{c}\text { Auto Covariance } \\
\text { Unemployment Rate }\end{array}$ & Cross Covariance \\
\hline 1 & 1.750 & 4.320 & .458 \\
2 & 1.578 & 2.499 & .391 \\
3 & 1.302 & 1.261 & .437 \\
4 & 1.023 & .566 & .266 \\
5 & .732 & .581 & -.032 \\
6 & .445 & .001 & -.071 \\
7 & .208 & -.509 & -.104 \\
8 & .064 & -.864 & -.130 \\
9 & -.010 & -.793 & -.167 \\
10 & -.051 & -.416 & -.187 \\
11 & -.063 & -.226 & -.171 \\
12 & -.056 & -.075 & -.095 \\
13 & -.028 & -.016 & -.034 \\
\hline \hline
\end{tabular}

Table 7

Phase and Coherence Between White Female Labor Force Participation Rates and Rates of Unemployment Among Blacks, 1950-1982

\begin{tabular}{crc}
\hline \hline Frequency & Phase & Coherence \\
\hline .0000 & -.000 & .272 \\
.0313 & .692 & .202 \\
.0625 & .714 & .074 \\
.0938 & -.406 & .003 \\
.1250 & .787 & .053 \\
.1563 & 1.315 & .029 \\
.1875 & 2.687 & .295 \\
.2188 & 2.819 & .605 \\
.2500 & 2.989 & .659 \\
.2813 & -3.036 & .402 \\
.3125 & 2.351 & .070 \\
.3438 & .747 & .272 \\
.3750 & .247 & .330 \\
.4063 & -.135 & .104 \\
.4375 & -1.466 & .167 \\
.4688 & -1.430 & .317 \\
.5000 & -.000 & .030 \\
\hline \hline
\end{tabular}

ence, a measure of correlation, (Table 7) tends to be small and unstable over most frequencies, implying the absence of a systematic and consistent interaction between the two series. In sum, spectral analysis of the data does not shed much light on the sensitivity of black unemployment to increased rates of entries into the labor market by apparently competing groups. Thus, while our results are inconclusive on this point, we cannot rule out the possibility that such substitution does occur.

\section{Conclusions and Implications}

This exploratory study has attempted to examine black-white unemployment differentials over the course of business cycles that have occurred from 1950 to 1982 and hopefully it could serve as a basis for future research in this area.

The empirical evidence presented is reassuring inasmuch as it suggests some improvements in the relative labor market position of 
minorities in recent years. While progress has occurred, our study suggests that blacks continue to be more severely affected than whites by recessions. It is highly possible that these improvements have been fostered by Civil Rights Legislation and a greater commitment on the part of our public and private institutions to aid the integration of minorities into the economic mainstream. Still, macroeconomic policy continues to be the most significant factor in shaping unemployment trends among sub-groups in the labor force. It has been shown that, at least in the short run, blacks tend to benefit more from an economic expansion and pay a heavier toll during the course of an economic downturn. Civil Rights leaders should, as a matter of practical policy, focus some attention on seeking and promoting full employment as a priority of great significance to minorities.

\section{Suggestions for Further Research}

As the analysis in this paper is based on highly aggregated data, it is felt that further investigation of underlying factors affecting patterns of unemployment among sub-groups in the labor force would be highly beneficial. Additional research could, for example, focus on a comparison of regional patterns of unemployment and national data to ascertain whether there are important variations in the relative market experience of blacks. This study suggests that minority gains (losses) in the labor market are closely tied to economic expansion (contraction). Since the South has shown higher growth rates than the nation as a whole in recent years, it could be hypothesized that blacks have made more gains in the South than in other regions.

Furthermore, the present study does not fully explore the types of cycles causing most of the variations in black and white unemployment rates. An in-depth analysis of these cycles may point out areas of economic activity that are more important to minorities than to the rest of the work force.

Consequently, we suggest a micro-oriented examination of the work force by race, occupation and industry groups to determine how they are affected by macroeconomic fluctuations.

\section{FOOTNOTES}

'The black category includes all persons who are observed in the enumeration process to be other than whites.

'Since the ratio is computed on the basis of percentage, the ratio will fall so long as the unemployment rate for blacks increases by a smaller percentage than the overall unemployment rate. For example, consider the following:

$\begin{array}{lcc} & \text { Period 1 } & \text { Period 2 } \\ \text { Black unemployment rate } & 10 & 12 \\ \text { Overall unemployment rate } & 6 & 8 \\ \text { Relative unemployment rate } & 1.667 & 1.5\end{array}$

As the unemployment rate increases by two percentage points for each group from period 1 to period 2 , the ratio falls; however, it would be misleading to conclude that blacks have improved their position in the labor market in period 2.

'It is known that construction and building activity is subject to cycles of 10 to 12 years duration. Construction cycles do not always coincide with fluctuations in general business activity. In light of their decreasing employment opportunities in agriculture, many blacks have found construction and related work to be a ready alternative to farm work.

\section{REFERENCES}

Bloomfield, P., The Fourier Analysis of Time Series: An Introduction, New York, Wiley, 1970.

Brillinger, David R., Time Series Data Analysis and Theory, San Francisco, Holden-Day, Inc., 1981.

Burns, Arthur F. and Wesley C. Mitchell, Measuring Business Cycles, National Bureau of Economic Research, 1946.

Gilman, Harry, "The White/Non-White Unemployment Differentials," Mark Perlman, ed., Human Resources in the Economy, Washington, D.C., Resources for the Future, Inc., 1963, pp. 75-113.

Gilroy, L. Curtis, "Black and White Unemployment: The Dynamics of the Differential," Monthly Labor Review, February 1974, pp. 38-47.

Hashemzadeh, Nozar and Michael Simmons, "The Impact of Changing Patterns in Female Labor Force Participation on Employment Prospects of Black Youth," research paper sponsored by the U.S. Department of Labor, Washington, D.C., 1983.

Malinvaud, Edmond, Statistical Methods of Econometrics, New York, North Holland and Publishing Company, 1980.

U.S. Bureau of Labor Statistics, Employment and Earning, Washington, D.C., February 1984, p. 33. 